
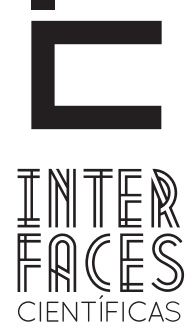

DIREITO

\title{
DA DESAPROPRIAÇÃO DO IMÓVEL RURAL POR DESCUMPRIMENTO DA FUNÇ̃̃̃O SOCIAL COM ÊNFASE NO ASPECTO AMBIENTAL: DAS SESMARIIAS À CONSTITUIÇ̄̃̃O FEDERAL DE 1988
}

\section{RESUMO}

0 presente artigo tem o objetivo de, partindo dos métodos bibliográfico e documental, analisar os principais aspectos históricos referentes à desapropriação do imóvel rural pelo descumprimento da função social, no Brasil, com destaque para a função socioambiental. Deste modo, o presente artigo aborda o tratamento legal dispensado à terra no que tange à sua função social, desde o regime das sesmarias, no Período Colonial, até a promulgação da Constituição Federal de 1988. Ademais, traça breve relato sobre o surgimento do latifúndio no Brasil.

\section{PALAVRAS-CHAVE}

Função social; Imóvel Rural; Descumprimento; Desapropriação.

\section{ABSTRACT}

This article aims to, starting from the bibliographic and documentary methods, analyze the main aspects related to the historical dispossession of rural property for failure of social function, in Brazil, with emphasis on the environmental function. Thus, this article addresses the legal treatment meted out to land in relation to its social function, since the system of land grants in the Colonial Period, until the promulgation of the 1988 Constitution. Moreover, traces brief account of the emergence of large estates in Brazil.

\section{KEYWORDS}

Social Function. Rural Property. Noncompliance. Expropriation. 


\section{RESUMEN}

Este artículo tiene como objetivo, a partir de métodos de fondos bibliográficos y documentales, analizar los principales aspectos relacionados con el despojo histórico de la propiedad rural para el fracaso de la función social, en Brasil, con énfasis en la función del medio ambiente. Por lo tanto, este artículo aborda el tratamiento jurídico dispensado a la tierra en relación con su función social, ya que el sistema de concesiones de tierras en la época colonial, hasta la promulga- ción de la Constitución de 1988. Por otra parte, traza brevemente el surgimiento de grandes haciendas en Brasil.

\section{PALABRAS CLAVE}

Función Social. Propiedad Rural. Incumplimiento. Expropiación.

\section{INTRODUÇ̄̃O}

A expressão função social da propriedade só foi inserida, na legislação brasileira, pela Lei de Terras de 1964. No entanto, como toda novidade legislativa, esse instituto surgiu de experiências históricas que, de algum modo, demonstraram a necessidade de sua inserção legislativa e, posteriormente, constitucional, sempre com vistas à garantia do bem-estar social.

Destaca-se que um dos aspectos relativos à função social da propriedade diz respeito à conservação e preservação dos recursos naturais existentes em dada propriedade. Depois, é importante salientar que a consequência do descumprimento da função social é a desapropriação do imóvel por parte do Estado e que, em se tratando de imóvel rural, destina-se o mesmo,

\section{MÉTODO}

No que tange às técnicas de investigação, a pesquisa tem caráter documental e bibliográfico. A pesquisa documental refere-se a documentos públicos e particulares, como documentos oficiais e publicações parlamentares. A pesquisa bibliográfica trata do

levantamento da bibliografia já publicada em forma de livros, revistas científicas, publicações avulsas, imprensa escrita, periódicos, anais, trabalhos científicos (LAKATOS; MARCONI; 2001, p. 56). 


\section{RESULTADOS E DISCUSSÃO}

Os resultados da pesquisa se confundem com os dados apresentados no item "conclusão" do presente trabalho. De igual modo, a discussão do tema objeto deste trabalho se encontra inserto no item "estudo teórico".

\section{ESTUDO TEÓRICO}

\subsection{A CRIAÇÃO DO LATIFÚNDIO NO BRASIL: RESPONSABILIDADE DO SISTEMA SESMARIAL?}

Conquanto se atribua ao sesmarialismo a causa principal do latifúndio brasileiro, não se pode negar que o conceito de sesmarias, tal como posto Código Filipino, demonstrava qualquer preocupação voltada ao cultivo da terra, enquanto condicionante do direito de propriedade. É o que se denota das palavras de Cândido Mendes de Almeida (apud SILVA, 2008, p. 42):

\begin{abstract}
Sesmarias são propriamente as dadas de terras, casais, ou pardieiros, que foram, ou são de alguns senhores, e que já em outro tempo foram lavradas e aproveitadas, e agora o não são. As quais terras e os bens assim danificados e destruídos podem e devem ser dados de sesmarias pelos sesmeiros, que para isto forem ordenados.
\end{abstract}

Da afirmação de Silva, já se percebe que no sistema sesmarial vigorava no Brasil, para a propriedade improdutiva o dever de ser devolvida ao Reino, de modo que aquele que não cultivasse a contento as terras sob sua posse, perdê-las-ia em favor de outrem que se dispusesse a cultivá-la, tornando-a, pois, produtiva. Tal consequência se assemelha ao que, atualmente, denomina-se de desapropriação de imóvel rural por descumprimento de sua função produtiva. Disto, também resta claro que o regime sesmarial não foi contrário ao capitalismo.

Também quanto à atribuição ao sistema sesmarial da grande responsabilidade pelo surgimento do latifúndio brasileiro, que perdura até os dias atuais, Costa Porto (apud SILVA, 2008, p. 43) salienta que tal sistema ocorreu de formas diversas em Portugal e no Brasil, ponderando que:

\begin{abstract}
Uma das principais distorções do nosso sesmarialismo - fruto em grande parte, do dezazo em ignorar as peculiaridades da Conquista, aplicando-lhe o disciplinamento imaginado para a Metrópole - ocorreria de respeito à estrutura fundiária e cuja síntese seria esta: enquanto no Portugal dos fins do século XIV, a prática do sesmarialismo gerou, em regra, a pequena propriedade, no Brasil foi a causa principal do latifúndio.
\end{abstract}

No mesmo sentido, leciona Silva (2008, p. 43):

Embora seja inegável a existência de diferenças muito grandes entre a metrópole e a Colônia, não é de todo correto atribuir ao sesmarialismo a causa principal do latifúndio brasileiro. Na realidade, a distância que separou os objetivos do regime de sesmarias, cuja criação fora motivada pelos problemas da agricultura portuguesa, e a prática do sesmarialismo na Colônia deveu-se, principalmente, às condicionantes históricas da colonização. A distorção do sentido primeiro do sistema significou, portanto, a adaptação do instituto jurídico criado em Portugal à realidade socioeconômica da Colônia. Adaptação forçada, que se fez aos poucos, por meio da prática da administração colonial.

Explica-se que os sistemas sesmariais brasileiro e lusitano se distinguiam, principalmente, porque tomaram a expressão "terras devolutas" em sentidos 
diversos: enquanto, no Brasil, a expressão designava terras vagas, sem dono, ainda que ocupadas por povos indígenas, em Portugal, remetia à ideia de "devolvido ao senhor original” (SILVA, 2008, p. 44).

\begin{abstract}
$\mathrm{Na}$ acepção estrita do termo, as terras devolutas na Colônia seriam aquelas que, doadas de sesmarias e não aproveitadas, retornavam à Coroa. Com o passar do tempo, as cartas de doação passaram a chamar toda e qualquer terra de devoluta; assim, consagrou-se no linguajar oficial e extraoficial devoluto como sinônimo de vago. Assim como a questão do domínio eminente, a utilização do termo "devoluto" levou grandes discussões, mesmo depois que a lei de 1850 redefiniu o significado do termo para poder aplicá-lo ao caso brasileiro; sobretudo, questionava-se a competência do poder público em legislar sobre terrenos que não eram "propriamente" devolutos. (SILVA, 2008, p. 44)
\end{abstract}

Por conseguinte, o que se viu, nos anos posteriores, foram doações feitas pelas autoridades coloniais sem a observância dos limites estabelecidos nas Ordenações do Reino, sendo que, muitas vezes, as áreas doadas eram imensas, desrespeitando-se ainda o prazo estipulado para tanto, findo o qual as terras, se não houvessem sido cultivadas conforme regras estabelecidas nas Ordenações, poderiam ser doadas a

\subsection{TRATAMENTO DISPENSADO À “FUNÇ̃̃O SOCIAL” E À “DESA- PROPRIAÇÃO" DO IMÓVEL RURAL ENTRE O REGIME SESMARIALE A LEI DE TERRAS DE 1850}

No período anterior à Lei de Terras de 1964 não há nada sobre previsão legal da função social da propriedade, menos ainda no que tange a seu aspecto ambiental. No entanto, sob o viés produtivista, percebe-se que a "ideia" da função social do imóvel rural já estava contida nas Ordenações do Reino que dispunham sobre o sistema das sesmarias. É o que demonstra nas linhas seguintes. pessoas distintas dos primitivos donatários. Ademais, a falta de rigor na fiscalização e cumprimento das normas relativas a tais doações contribuiu para que várias doações fossem feitas a um mesmo indivíduo (SILVA, 2008, p. 43-47).

No período compreendido entre a cessação da concessão das sesmarias e a promulgação da Lei $n^{\circ}$. 601/1850 - Lei de Terras, o latifúndio ainda mais se consolidou no Brasil. É o que enfatiza Smith (1990, p. 304):

\begin{abstract}
O interregno que vai de 1822 a 1850 põe em evidência um processo de amplo apossamento de terras, que caracterizará, no País, a formação do latifúndio, na sua forma mais acabada. 0 latifúndio avançará sobre as pequenas posses, expulsando o pequeno posseiro em algumas áreas, num deslocamento constante sobre as fronteiras de terras abertas.
\end{abstract}

Para historiadores como Costa Porto e Lígia Osório Silva, portanto, a despeito de existirem opiniões diversas entre os estudiosos, o sesmarialismo não criou o latifúndio brasileiro, mas apenas o consolidou. Esses estudiosos atribuem tal criação ao próprio sistema político colonial brasileiro.

O sistema sesmarial brasileiro (1530-1822) “[...] correspondeu à ordenação jurídica da apropriação territorial que a metrópole impôs à Colônia enquanto durou seu domínio sobre ela" (SILVA, 2008, p. 41). Tal sistema já impunha ao sesmeiro a obrigação de cultivar as terras a ele dadas a esse título, ficando claro o cunho produtivista daquele sistema. Pertinentes, nesse sentido, as lições de Silva (2008, p. 41): 
O objetivo básico da legislação era acabar com a ociosidade das terras, obrigando ao cultivo sob pena de perda de domínio. Aquele senhorio que não cultivasse nem desse em arrendamento suas terras perdia o direito a elas, e as terras devolutas (devolvidas ao senhor origem, à Coroa) eram distribuídas a outrem para que as lavrasse e aproveitasse e fosse respeitado, assim, o interesse coletivo.

Como já dito anteriormente, o regime sesmarial tinha por fundamento o cultivo da terra, denotando, claramente, o cunho produtivista da propriedade, que, atualmente, inclusive, é um dos requisitos ao cumprimento da função social da terra.

Findo o regime sesmarial, por resolução do então Imperador D. Pedro, datada de 17 de julho de 1822, a menos de dois meses da proclamação da Independência, em 7 de setembro do mesmo ano, a posse passou a ser utilizada como instituto legitimador do uso e cultivo da terra e "a partir daí, o regime de franco apossamento de terras representa um quadro em que o Estado praticamente sai de cena, na questão do ordenamento legal da apropriação de terras" (SMITH, 1990, p. 239).

Com o fim das sesmarias, o direito de posse, então, passou a ser condicionado ao real cultivo da terra, o que também já demonstra a "ideia" do que, mais tarde, constituiria um dos requisitos da observância da função social: 0 aspecto produtivista. Com razão, asseveram Motta e Zarth (2008, p. 87):

[...] a consagração da primazia da posse em detrimento do documento de sesmaria parecia refletir o reconhecimento daquele que detém a posse como legítimo ocupante, já que ao ocupá-la o lavrador estaria a exercer o cultivo, princípio legitimador do acesso à terra, desde a instalação do sistema sesmarial em áreas coloniais.

Elaborada por um Conselho de Estado e Outorgada pelo Imperador D. Pedro I, a Constituição Política do Império do Brasil, de 25 de março de 1824, garantia o direito de propriedade em toda a sua plenitude, fazendo-o nos seguintes termos:

Art. 179. A inviolabilidade dos Direitos Civis, e Políticos dos Cidadãos Brasileiros, que tem por base a liberdade, a segurança individual, e a propriedade, é garantida pela Constituição do Império, pela maneira seguinte.

[...]

XXII - É garantido o Direito de Propriedade em toda a sua plenitude. Se o bem público legalmente verificado exigir o uso, e emprego da Propriedade do Cidadão, será ele previamente indenizado do valor dela. A Lei marcará os casos, em que terá lugar esta única exceção, e dará as regras para se determinar a indenização. (ortografia atualizada pelo autor).

Nota-se que também a Constituição Imperial de 1824, embora garantisse o direito de propriedade em toda sua plenitude, e conquanto não se tenha utilizado da expressão "função social”, já se propunha a excepcionar o uso ou emprego desta quando o interesse público o exigisse, mediante prévia indenização ao proprietário. De igual modo, a Constituição Imperial não tratou da desapropriação do imóvel.

Para Motta e Zarth (2008, p. 87), “o reconhecimento da posse para por fim àquele sistema era o ápice de um processo de questionamento acerca do direito do sesmeiro, que, mesmo descumprindo a exigência de cultivo, se consagrara como proprietário da terra". De fato, somente com o advento da Lei de Terras de 1850, a posse e a sesmaria passaram a contar com regulamentação, conforme escreve Smith (1990, p. 330):

A Lei de Terras regulara finalmente a posse e a sesmaria em comisso. A rigor, não fugira juridicamente de certas cláusulas que a legislação de terras portuguesa sempre considerava - a legitimação, em última instância, pela utilização efetiva. Era uma diretriz que, mesmo não obedecida, fazia, como fizera anteriormente na colônia, criar um fosso entre a apropriação privada e o reconhecimento público da propriedade fundiária. Principalmente porque limitava a área da propriedade. 
Infere-se que também a Lei de Terras de 1850 não previu, expressamente, a função social da propriedade, menos ainda condicionava o direito de propriedade a tal função, mesmo porque a Constituição Outorgada de 1824 garantia o direito de propriedade em toda a sua plenitude. Todavia, tal qual o regime sesmarial, aquele diploma legal continuou a prever como fundamento legitimador da posse e da propriedade a efetiva utilização da terra.

Sob a égide da Lei de Terras de 1850, o cultivo da terra e a morada habitual passaram, inclusive, a ser utilizados como elementos definidores de disputas de terras entre sesmeiros e posseiros, segundo pontua Silva (2008, p. 154):

Seriam revalidadas as sesmarias ou outras concessões do governo-geral ou provincial que se achassem cultivadas, ou princípios de cultura e morada habitual do respectivo sesmeiro (ou seu representante), mesmo que nenhuma das outras condições estabelecidas originalmente tivesse sido cumprida. [...] Em casos de disputa entre posseiros e sesmeiros, o critério mais importante seria sempre o de favorecer aquele que efetivamente cultivasse as terras (a lei especificava os casos). Estabelecia também que não se entendiam por "princípio de cultura" os simples roçados, derrubada de matos, queimadas, levantamentos de rancho e outros atos de semelhante natureza.

A ideia defendida por Messias Junqueira - mencionada por Silva (2008, p. 174) - de que a Lei de Terras de 1850 teve o pensamento fixo de respeitar o título de terras do indivíduo que, concomitantemente, atendesse aos requisitos de cultura efetiva e morada habitual, revela que, ainda que implicitamente, a ideia da função social produtiva da propriedade era elemento a que se atentava o diploma legal em comento. Nesse sentido, aduz Silva (2008, p. 175) que:

Portanto, para o autor em questão, o espírito da lei, ao identificar terra devoluta com terra inculta, era estimular o cultivo da terra e respeitar todo aquele que efetivamente a cultivasse. Tanto isso era verdade, argumenta Messias Junqueira, que a lei, em seu art. $8^{\circ}$ garantia a posse da parte com cultura efetiva e morada habitual do sesmeiro ou posseiro que não cumprisse as determinações da própria lei. É verdade que o artigo Il afirmava que sem o título de propriedade, que só podia ser obtido por meio do cumprimento das determinações da lei (em especial a medição), o possuidor não poderia vender, nem hipotecar suas terras. Ele continuava possuidor dos terrenos que efetivamente cultivasse, mas não se tornava proprietário. Mas, afirma o autor, o artigo $8^{\circ}$, combinado com o art. 179, inciso XXII da Constituição imperial de 25 de março de 1824 (que garantia o direito de propriedade em toda a sua plenitude), protegeu os ditos possuidores da ameaça contida no artigo $2^{\circ}$, que jamais foi cumprida.

O legado deixado pelo regime de sesmarias pode ser percebido ainda nos dias de hoje, pois, em muitos casos, este regime continua a nortear concepções de direito à terra, mormente no que tange ao efetivo uso em detrimento do próprio direito de propriedade. É o que sustentam Motta e Zarth (2008, p. 179):

\begin{abstract}
Ainda hoje, quando um posseiro da Amazônia justifica seu direito à terra, ele o faz invocando o direito que teria sido gerado pelo trabalho na terra. Ao mesmo tempo, reclama e proclama que seu direito está referido aos frutos de seu trabalho, que por serem seus está no direito de cedê-los ou vendê-los. A concepção de que é preciso ocupar a terra com trabalho (na derrubada da mata e no seu cultivo) antes de obter reconhecimento de direito, era próprio do regime sesmarial. Do mesmo modo, a concepção de que o trabalho gera direito de propriedade sobre os frutos do trabalho também era própria desse regime fundiário. Nele, o domínio estava separado da posse. 0 domínio era da Coroa.
\end{abstract}

Conclui-se que mesmo com o fim das sesmarias, seu fundamento - o de que a propriedade da terra se legitima pelo trabalho - subsistiu nos períodos históricos ulteriores, permanecendo até os dias atuais, em que se continua a exigir que a terra produza, como condição de manutenção da grande propriedade. Assim, pode-se afirmar que, embora nos períodos históricos brasileiros consistentes na Colônia, Império e República Velha, não se pudesse falar em previsão legal da função social da propriedade, a ideia desta, sob o aspecto produtivista, esteve sempre contida nas legislações relativas à posse e à propriedade da terra, ainda quando a Constituição Imperial de 1824 garantia o direito de propriedade em toda sua plenitude. 


\subsection{TRATAMENTO DISPENSADO À FUNCÕO SOCIAL E À DESAPRO- PRIAÇ̃̃O DO IMÓVEL RURAL PELA LEI DE TERRAS DE 1964 E PELA CONSTITUIÇÃO FEDERAL DE 1988}

Em seu art. 186 e incisos, a Constituição Federal de 1988 explicita os requisitos a serem cumpridos pela propriedade rural com vistas ao cumprimento de sua função social, da seguinte forma:

\footnotetext{
Art. 186. A função social é cumprida quando a propriedade rural atende, simultaneamente, segundo critérios e graus de exigência estabelecidos em lei, aos seguintes requisitos:

I - aproveitamento racional e adequado;

II - utilização adequada dos recursos naturais disponíveis e preservação do meio ambiente;

III - observância das disposições que regulam as relações de trabalho;

IV - exploração que favoreça o bem-estar dos proprietários e dos trabalhadores.
}

Cumpre ressaltar que as constituições anteriores à vigente não traziam proteção específica ao meio ambiente natural. Ao contrário, muitas vezes incentivou o uso dos recursos naturais sem qualquer regramento, interessadas que estavam no desenvolvimento econômico do País. Todavia, como se infere do supramencionado dispositivo magno, um dos requisitos atinentes à observância da função social da propriedade, instituto também previsto no art. $5^{\circ}$, inciso XXIII, da Constituição Federal, diz respeito exatamente à "utilização adequada dos recursos naturais disponíveis e preservação do meio ambiente" (art. 186, II, da $\mathrm{CF} / 88$ ).

O preceito acima aludido, como outros espalhados pelo texto da Carta Política de 1988, especialmente, 0 art. 225, denota a ampla proteção agora dedicada ao meio ambiente, já que "o conteúdo da propriedade não reside num só elemento. Há o elemento individual, que possibilita o gozo e o lucro para o proprietário. Mas outros elementos aglutinam-se a esse: além do fator social, há o componente ambiental" (MACHADO, 2010, p. 158).
De outra banda, frisa-se que o uso da expressão função social da propriedade não é propriamente uma inovação da Carta Magna de 1988, conquanto o seja em termos puramente constitucionais. De fato, tal terminologia foi utilizada pela primeira vez na legislação pátria apenas com o advento da Lei de $n^{0}$. 4.504, de 30 de novembro de 1964 - Estatuto da Terra de 1964, exatamente no momento de ruptura política provocada pelo Golpe Militar de 1964.

O Estatuto da Terra de 1964 já previa o instituto da função social, nos seguintes dispositivos:

\begin{abstract}
Art. $2^{\circ} E$ assegurada a todos a oportunidade de acesso à propriedade da terra, condicionada pela sua função social, na forma prevista nesta Lei.

$\S 1^{\circ} \mathrm{A}$ propriedade da terra desempenha integralmente a sua função social quando, simultaneamente:

a) favorece o bem-estar dos proprietários e dos trabalhadores que nela labutam, assim como de suas famílias;

b) mantém níveis satisfatórios de produtividade;

c) assegura a conservação dos recursos naturais;

d) observa as disposições legais que regulam as jus-

tas relações de trabalho entre os que a possuem e a cultivem.

$\S 2^{\circ}$ É dever do Poder Público:

b) zelar para que a propriedade da terra desempenhe sua função social, estimulando planos para a sua racional utilização, promovendo a justa remuneração e o acesso do trabalhador aos benefícios do aumento da produtividade e ao bem-estar coletivo.
\end{abstract}

Art. 12. À propriedade privada da terra cabe intrinsecamente uma função social e seu uso é condicionado ao bem-estar coletivo previsto na Constituição Federal e caracterizado nesta Lei.

Art. 13. O Poder Público promoverá a gradativa extinção das formas de ocupação e de exploração da terra que contrariem sua função social.

Art. 18. À desapropriação por interesse social tem por fim:

a) condicionar o uso da terra à sua função social; 
Art. 47. Para incentivar a política de desenvolvimento rural, o Poder Público se utilizará da tributação progressiva da terra, do Imposto de Renda, da colonização pública e particular, da assistência e proteção à economia rural e ao cooperativismo e, finalmente, da regulamentação do uso e posse temporários da terra, objetivando:

I - desestimular os que exercem o direito de propriedade sem observância da função social e econômica da terra;

Observa-se também que o Estatuto da Terra já tratava do respeito, conservação e preservação aos recursos naturais enquanto condição de atendimento à função social do imóvel rural (art. $\left.2^{\circ}, \S 1^{\circ}, \mathrm{c}\right)$, não sendo também esta propriamente uma inovação da Carta Magna de 1988, conquanto o seja em termos constitucionais.

Vê-se a condicionamento do direito de propriedade à observância também de sua função socioambiental surge do desenvolvimento de uma consciência ecológica, da necessidade de conservação e preservação dos recursos naturais, vez que, ao contrário do que pensava o homem primitivo, estes não são inesgotáveis. Sob este prisma, salienta Graziano Neto (1985, p. 80):

As consequências de um domínio "irracional" sobre a Natureza podem ser ameaçadoras à própria sobrevivência do homem, que somente através da ciência pode encontrar povos antigos, ao atearem fogo nas florestas para caçarem ou derrubarem bosques para a prática da agricultura, desconheciam completamente as consequências de atos. Na verdade, o homem sempre competiu com a Natureza com certo grau de "irracionalidade".

Destaca ainda Graziano Neto (1985, p. 82) que:

A Natureza tem reagido às agressões recebidas e, ao lado de conquistas brilhantes da sociedade, assistimos atualmente a graves ameaças à sobrevivência humana, como a poluição do ar nas grandes cidades, os alimentos contaminados, as alterações climáticas, os solos destruídos, as doenças da civilização (como o câncer) etc.
Por consequência, o descumprimento da função social da propriedade acarreta sua desapropriação, conforme preceito contido no art. 184, caput, da Lei Maior, ipsis litteris:

Art. 184. Compete à União desapropriar por interesse social, para fins de reforma agrária, o imóvel rural que não esteja cumprindo sua função social, mediante prévia e justa indenização em títulos da dívida agrária, com cláusula de preservação do valor real, resgatáveis no prazo de até vinte anos, a partir do segundo ano de sua emissão, e cuja utilização será definida em lei.

Também a desapropriação já era instituto previsto no art. 18, a, do Estatuto da Terra, sendo assim definida nas palavras de Ferreira (1988, p. 185):

A desapropriação é um ato de direito público mediante o qual a administração, com base na necessidade pública, na utilidade pública ou no interesse social, desvincula um bem de seu legítimo proprietário para transferir sua propriedade a um ente estatal ou a particular, com prévia e justa indenização.

Sobre esta, Sampaio (1988, p. 11-12) ainda sustenta que:

Em um Estado de Direito, o poder público não pode retirar, arbitrariamente, a propriedade da terra. Só poderá fazê-lo quando esse direito não estiver sendo exercitado de acordo com a lei. Por isso, a lei precisa conter dispositivos que possibilitem a clara separação entre os proprietários que estão exercitando seu direito adequadamente e os que não o estão fazendo. Para evitar o arbítrio das autoridades, esses dispositivos devem explicitamente declarar as situações que autorizam o Estado a desapropriar um imóvel. Na legislação chilena pré-Pinochet, usava-se a expressão "causales de expropriacion" para disciplinar essa matéria; na terminologia jurídica brasileira, adotou-se o conceito "função social da propriedade".

Como consta do já citado art. 184, caput, da Carta Magna, à desapropriação de imóvel rural precederá a indenização justa e prévia. Por indenização justa firmou-se o entendimento de que é aquela correspondente ao valor de mercado do imóvel. To- 
davia, em vésperas de ser promulgada a Constituição Federal de 1988, Sampaio (1988, p. 11) se mostrava contrário a esta forma de cálculo do valor da indenização e de pagamento, explicando que:

\begin{abstract}
Duas as características da economia brasileira, uma terra não se valoriza apenas em função da sua capacidade produtiva, mas também pelo fato de constituir um meio de preservar riqueza. Ao considerar esses dois elementos no cálculo do justo valor - o seu custo histórico e a valorização - a legislação brasileira incide no paradoxo de dar um prêmio financeiro aos especuladores. Ou seja, os fatores que determinam a intervenção corretiva do estado na esfera econômico-social do mundo rural, quais sejam o monopólio da terra e o seu uso distorcido como reserva de valor, acabam sendo privilegiados. [...]

A forma de pagamento só pode ser a prazo. De outra forma, o governo não teria recurso financeiro para realizar um número de desapropriações compatível com o impacto econômico, social e político que o processo precisa alcançar, a fim de adquirir magnitude suficiente para reverter tendências profundamente entranhadas no mundo rural.
\end{abstract}

No período anterior à promulgação da Constituição Federal de 1988, o valor da indenização em caso de desapropriação de imóvel rural corresponderia àquele declarado para fins do imposto territorial rural (Ato Institucional de $n^{0}$. 09/1969). No entanto, tal critério foi declarado inconstitucional pelo então Tribunal Federal de Recursos, não sendo restabelecido pela Carta Magna de 1988. Nesse sentido, ao se referir ao fato de que as terras desapropriadas têm como destino a reforma agrária, que teria diminuída a dificuldade de concretização se o valor da indenização fosse calculado daquela forma, Silva (1998, p. 16) teceu as seguintes críticas ao Texto Constitucional vigente:

Agora, em 1988, a despeito do agravamento da questão da posse da terra em nosso País, a Constituinte de 1987/88 recuou duplamente, restabelecendo o prévio pagamento das indenizações e omitindo-se no restabelecimento do critério para fixação do "justo preço".
Outra crítica feita por Silva (1988, p. 16) à Constituição Federal de 1988 atine à vedação da desapropriação da propriedade produtiva (art. 185, II), o que, para ele, impossibilita qualquer mudança significativa na estrutura fundiária brasileira:

[...] mas a questão da "propriedade produtiva" precisa aqui ser colocada. Trata-se, na verdade, de um dos mais sérios recuos já ocorridos na história das Constituições brasileiras e que, na prática, sepultou definitivamente a possibilidade de realizar qualquer mudança estrutural na agricultura brasileira, sob a égide da nova Carta.

De fato, ao dispor, no inciso II do art. 185, que a chamada "propriedade produtiva" é não-suscetível de desapropriação, a CF de 1988 introduziu na prática tamanhas dificuldades de ordem legal, agronômica e operacional, que inviabiliza por completo qualquer tentativa séria de mudar a nossa estrutura fundiária. [...]

Na prática, a vigorar o princípio de que terras produtivas não podem ser desapropriadas, restarão apenas, para essa finalidade, as terras improdutivas. E se, eventualmente, os tribunais se fixarem no conceito de fertilidade (mais preciso), ficarão para a reforma agrária apenas os carrascais, charcos, arciões, piçarras e pirambeiras. E isso, é claro, nem os trabalhadores nem a racionalidade aceitarão...

Tendo em vista que é nas grandes propriedades rurais, que quase sempre lidam com agricultura e pecuária, dispondo, muitas vezes, de recursos tecnológicos muito avançados, que se verifica o descumprimento da função social da propriedade resultante da ocorrência de danos ambientais de grande monta, notadamente, queimadas e desmatamentos de florestas e poluição dos recursos hídricos, pertinentes se fazem as palavras de Graziano Neto (1985, p. 86):

O desenvolvimento tecnológico da agricultura no capitalismo tem instalado sistemas de produção altamente instáveis, que requerem por sua vez técnicas cada vez mais complexas para seu controle. 0 resultado final das constantes tentativas de "dominar" a Natureza é a própria destruição da Natureza, além dos outros problemas ecológicos que serão tratados adiante. 
Graziano Neto (1985, p. 95) ainda assevera que:

Juntos, o sistema latifundiário, o isolamento político e administrativo da colônia, a farta disponibilidade de terras e a ausência de um passado tecnológico (excluída a incipiente agricultura indígena) explicam a devastação da Natureza desde muito antes do processo de modernização recente. Este, no entanto, veio agravar decisivamente a devastação secular da Natureza [...].
Nota-se que, quando se tem em foco a desapropriação do imóvel rural, para fins de reforma agrária, a principal crítica relativa à Constituição Federal de 1988 reside na vedação da desapropriação do grande imóvel produtivo, ainda quando descumpra sua função social, o que, por consequência, inviabiliza a concretização de uma reforma agrária significativa.

\section{CONCLUSÃO}

Embora a função social da propriedade só tenha sido expressamente prevista pelo Estatuto da Terra de 1964, a ideia que ela encerra - a de que a propriedade só se legitima se obedece a interesses da coletividade, para tanto obedecendo a requisitos previamente estabelecidos em lei - sempre esteve presente no direito pátrio, desde o regime sesmarial até a Constituição de 1988.

Até a Lei de Terras de 1964, a ideia da função social se limitou ao aspecto produtivista da propriedade, primando-se, sempre e tão somente, pelo cultivo da terra como princípio legitimador da posse. No entanto, a Lei de Terras de 1964 não só estatui, expressamente, que o direito de propriedade se condiciona ao cumprimento de sua função social, como ainda, desvinculou-o do cunho meramente produtivista da terra, prevendo, dentre este e outros requisitos, e em razão do desenvolvimento de certa consciência ecológica, a necessidade de conservação e preservação dos recursos naturais.
No que tange à desapropriação do imóvel rural que descumpra a sua função social, enfatizando-se ao aspecto ambiental, demonstrou-se que as principais críticas ao Texto Constitucional vigente se referem à vedação, pela própria Constituição Federal de 1988 da desapropriação da propriedade produtiva, bem como ao fato de o mesmo não ter constitucionalizado, como critério de cálculo da prévia indenização, o valor declarado para fins do Imposto Territorial Rural. Tais críticas são ainda mais severas quando se tem se em vista que estes fatos impossibilitam, sobremaneira, a concretização de uma reforma agrária significativa, finalidade última do próprio instituto da função social.

Por todo o exposto, conclui-se que a função social da terra, que visa à ocupação racional da mesma, impõe restrições ao caráter individualista e absolutista do direito de propriedade, sendo elemento constitutivo e não meramente condicionante do direito de propriedade. 


\section{REFERÊNCIAS}

BRASIL. Constituição da República Federativa do Brasil de 1988. In: <http://www.planalto.gov.br/ccivil_03/ Constituicao/Constituicao.htm> Acesso em 31 jul 2013, às 11h23min.

BRASIL. Constituição Política do Império do Brasil, de 25 de março de 1824. In: <http://www.planalto.gov.br/ ccivil_03/constituicao/constituicao24.htm> Acesso em 31 jul 2013, às 10h23'min.

BRASIL. Lei nº . 4.504, de 30 de novembro de 1964. Dispõe sobre o Estatuto da Terra, e dá outras providências. Brasília-DF: Diário Oficial da União de 31 nov 1964.

FERREIRA, Pinto. Curso de Direito. 3 ed. rev. e atual. São Paulo: Saraiva, 1998.

GRAZIANO NETO, Francisco. Questão agrária e ecologia: crítica da moderna da agricultura. 2 ed. São Paulo: Editora Brasiliense, 1985.

MACHADO, Paulo Affonso Leme. Direito Ambiental Brasileiro. 18 ed. rev. atual. e ampl. São Paulo: Malheiros Editores, 2010.

LAKATOS, Eva Maria; MARCONI, Marina de Andrade. Fundamentos de Metodologia Científica. 7 ed. São Paulo: Atlas, 2010

MOTTA, Márcia Maria Menendes; ZARTH, Paulo (orgs.). Formas de resistência camponesa: visibilidade e diversidade de conflitos ao longo da história. São Paulo: Editora UNESP; Brasília-DF: Ministério do Desenvolvimento Agrário, NEAD, 2008.

SAMPAIO, Plínio de Arruda. A Reforma Agrária. In: Revista da Associação Brasileira de Reforma Agrária (ABRA). Ano 18, nº. 02. Ago a Nov 1988.

SILVA, Lígia Osório. Terras devolutas e latifúndio: efeitos da lei de 1850. 2 ed. Campinas - SP: Editora da Unicamp, 2008.

SILVA, José Gomes da. Reforma agrária na Constituição Federal de 1988: Uma avaliação crítica. In: Revista da Associação Brasileira de Reforma Agrária (ABRA). ano 18. N. 2. Agosto a novembro 1988, p. 05- 20.

SMITH, Roberto. Propriedade da Terra \& transição: estudo da formação da propriedade privada da terra e transição para o capitalismo no Brasil. São Paulo: Brasiliense, 1990. 
